\title{
The Case Analysis of the Scandal of Enron
}

\author{
Yuhao Li \\ Huntsman School of Business, Utah State University, Logan city, U.S.A \\ E-mail: wyl_2001_ren@126.com, carolee1989@gmail.com
}

\begin{abstract}
The Enron scandal, revealed in October 2001, eventually led to the bankruptcy of the Enron Corporation, an American energy company based in Houston, Texas, and the dissolution of Arthur Andersen, which was one of the five largest audit and accountancy partnerships in the world. In addition to being the largest bankruptcy reorganization in American history at that time, Enron undoubtedly is the biggest audit failure. It is ever the most famous company in the world, but it also is one of companies which fell down too fast. In this paper, it analysis the reason for this event in detail including the management, conflict of interest and accounting fraud. Meanwhile, it makes analysis the moral responsibility From Individuals' Angle and Corporation's Angle.
\end{abstract}

Keywords: Enron scandal, Accounting fraud, Moral responsibility, Analysis

\section{Review of Enron's Rise and Fall}

Throughout the late 1990s, Enron was almost universally considered one of the country's most innovative companies -- a new-economy maverick that forsook musty, old industries with their cumbersome hard assets in favor of the freewheeling world of e-commerce. The company continued to build power plants and operate gas lines, but it became better known for its unique trading businesses. Besides buying and selling gas and electricity futures, it created whole new markets for such oddball "commodities" as broadcast time for advertisers, weather futures, and Internet bandwidth.

Enron was founded in 1985, and as one of the world's leading electricity, natural gas, communications and pulp and paper companies before it bankrupted in late 2001, its annual revenues rose from about $\$ 9$ billion in 1995 to over $\$ 100$ billion in 2000 . At the end of 2001 it was revealed that its reported financial condition was sustained substantially by institutionalized, systematic, and creatively planned accounting fraud. According to Thomas (2002), the drop of Enron's stock price from $\$ 90$ per share in mid-2000 to less than $\$ 1$ per share at the end of 2001, caused shareholders to lose nearly $\$ 11$ billion. And Enron revised its financial statement for the previous five years and found that there was \$586million in losses. Enron fall to bankruptcy on December 2, 2001.

One of the lessons of the Internet boom is that it's often difficult for analysts to understand and evaluate new kinds of businesses. And executives like Mr. Skilling, who once swore at an analyst during a conference call for asking a pointed question about Enron's balance sheet, don't do much to foster the kind of open inquiry that could lead to better information.

But the Enron debacle is also emblematic of another problem that has become all too evident in the last few years: Wall Street's loss of objectivity. Investment banks make far more money from underwriting or merger deals than they do from broker fees. Analysts at these firms often face conflicting loyalties. They can be put in the position of having to worry as much about whether a chief executive might find a report offensive as whether an investor might find it helpful.

\section{The Causes of Enron's bankruptcy}

\subsection{Truthfulness}

The lack of truthfulness by management about the health of the company, according to Kirk Hanson, the executive director of the Markkula Center for Applied Ethics. The senior executives believed Enron had to be the best at everything it did and that they had to protect their reputations and their compensation as the most successful executives in the U.S.

The duty that is owed is one of good faith and full disclosure. There is no evidence that when Enron's CEO told the employees that the stock would probably rise that he also disclosed that he was selling stock. Moreover, the employees would not have learned of the stock sale within days or weeks, as is ordinarily the case. Only the investigation surrounding Enron's bankruptcy enabled shareholders to learn of the CEO stock sell-off before February 14, 2002 which is when the sell-off would otherwise have been disclosed. Why the delay? The stock was sold to the company to repay money that the CEO owed Enron - and the sale of company stock qualifies as 
an exception under the ordinary director and officer disclosure requirement. It does not have to be reported until 45 days after the end of the company's fiscal year. (The Conference Board, Inc., 845)

\subsection{Interest}

It has been suggested that conflicts of interest and a lack of independent oversight of management by Enron's board contributed to the firm's collapse. Moreover, some have suggested that Enron's compensation policies engendered a myopic focus on earnings growth and stock price. In addition, recent regulatory changes have focused on enhancing the accounting for SPEs and strengthening internal accounting and control systems. We review these issues, beginning with Enron's board. (Gillan SL, Martin JD, 2007)

The conflict of interest between the two roles played by Arthur Andersen, as auditor but also as consultant to Enron. While investigations continue, Enron has sought to salvage its business by spinning off various assets. It has filed for Chapter 11 bankruptcy, allowing it to reorganise while protected from creditors. Former chief executive and chairman Kenneth Lay has resigned, and restructuring expert Stephen Cooper has been brought in as interim chief executive. Enron's core business, the energy trading arm, has been tied up in a complex deal with UBS Warburg. The bank has not paid for the trading unit, but will share some of the profits with Enron.

\subsection{Enron and the reputation of Arthur Andersen}

The revelation of accounting irregularities at Enron in the third quarter of 2001 caused regulators and the media to focus extensive attention on Andersen. The magnitude of the alleged accounting errors, combined with Andersen's role as Enron's auditor and the widespread media attention, provide a seemingly powerful setting to explore the impact of auditor reputation on client market prices around an audit failure. $\mathrm{CP}$ investigates the share price reaction of Andersen's clients to various information events that could lead investors to revise their beliefs regarding Andersen's reputation.( Nelson KK, Price RA, Rountree BR, 2008)

Perhaps most damaging to Andersen's reputation was their admission on January 10, 2002 that employees of the firm had destroyed documents and correspondence related to the Enron engagement. For a sample of S\&P 1500 firms, CP reports that in the 3-day window following the shredding announcement $(0,+2)$, Andersen clients experienced a significant $-2.03 \%$ market reaction, and this reaction was significantly more negative than for Big 4 clients. Andersen's Houston office clients, where Enron was headquartered, experienced an even stronger negative market reaction than Andersen's non-Houston clients.2 Overall, CP concludes the shredding announcement had a significant impact on the perceived quality of Andersen's audits, and that the resulting loss of reputation had a negative effect on the market values of the firm's other clients.

In this study, we report new findings that shed light on whether this event study evidence is consistent with an auditor reputation effect. In so doing, we do not suggest that auditor reputation does not matter. As discussed above, there is ample evidence that reputation is important to auditors and their clients. Rather, our purpose is to determine whether client returns around Andersen's shredding announcement and related events can be considered evidence of a reputation effect, or whether the results are confounded by other effects.

\subsection{An important factor: accounting fraud (using "mark to market” and SPE as tools)}

\subsubsection{Mark to market}

As a public company, Enron was subject to external sources of governance including market pressures, oversight by government regulators, and oversight by private entities including auditors, equity analysts, and credit rating agencies. In this section we recap the key external governance mechanisms, with emphasis on the role of external auditors. This method requires that once a long-term contract was signed, the amount of which the asset theoretically will sell on the future market is reported on the current financial statement.

In order to keep appeasing the investors to create a consistent profiting situation in the company, Enron traders were pressured to forecast high future cash flows and low discount rate on the long-term contract with Enron. The difference between the calculated net present value and the originally paid value was regarded as the profit of Enron. In fact, the net present value reported by Enron might not happen during the future years of the long-term contract.

There is no doubt that the projection of the long-term income is overly optimistic and inflated.

\subsubsection{SPE-Special Purpose Entity}

Accounting rule allow a company to exclude a SPE from its own financial statements if an independent party has control of the SPE, and if this independent party owns at least 3 percent of the SPE.

Enron need to find a way to hide the debt since high debt levels would lower the investment grade and trigger 
banks to recall money.

Using the Enron's stock as collateral, the SPE, which was headed by the CFO, Fastow, borrowed large sums of money. And this money was used to balance Enron's overvalued contracts. Thus, the SPE enable the Enron to convert loans and assets burdened with debt obligations into income.

In addition, the taking over by the SPE made Enron transferred more stock to SPE.

However, the debt and assets purchased by the SPE, which was actually burdened with large amount of debts, were not reported on Enron's financial report.

The shareholders were then misled that debt was not increasing and the revenue was even increasing.

\section{Prisoner's dilemma shown in Enron's case}

At the time of the firm's collapse, Enron was engaged in a wide range of activities including energy production and the trading of energy-related commodities and derivatives. As such, many of its activities were potentially subject to oversight by the Commodities and Futures Trading Commission (CFTC) or the Federal Energy Regulatory Commission (FERC). The CFTC's primary mission is to ensure that the commodity futures and options markets operate in an open and competitive manner, while the FERC regulates the interstate transmission and market for energy products. Of course, the primary source of federal oversight for publicly traded firms is the Securities and Exchange Commission (SEC). We discuss each of these in turn.

In the zero-sum game, each party is trying to secure more gains for themselves even if the best outcome is cooperating with each other. Obviously, to pursue maximum profits, wrong doings like accounting fraud will harm the shareholders' interests. Arthur Andersen, as auditor but also as consultant to Enron, has to be responsible for both managers and shareholders since the provided accounting information has a direct influence on economic benefits of both parties. Clearly, the managers and Arthur Andersen chose betraying the shareholders to maximize their self interests.

\section{Who was morally responsible for the collapse of ENRON?}

\subsection{From Individuals' Angle}

As corporate acts originate in the choices and actions of human individuals, it is these individuals who must be seen as the primary bearers of moral duties and moral responsibility.

The then chairman of the board, Kenneth Lay, and CEO, Jeffrey Skilling, to allowed the then CFO, Andrew Fastow, to build private cooperate institution secretly and then transfered the property illegally. The CFO, Andrew Fastow, violated his professional ethics and took the crime of malfeasance.

When the superior, the chairman of the board of Kenneth Lay and CEO Jeffrey Skilling, ordered conspiratorial employees to carry out an act that both of them knowing is wrong, these employees are also morally responsible for the act.

The courts will determine the facts but regardless of the legal outcome, Enron senior management gets a failing grade on truth and disclosure. The purpose of ethics is to enable recognition of how a particular situation will be perceived. At a certain level, it hardly matters what the courts decide. Enron is bankrupt - which is what happened to the company and its officers before a single day in court. But no company engaging in similar practices can derive encouragement for any suits that might be terminated in Enron's favor. The damage to company reputation through a negative perception of corporate ethics has already been done.

Arthur Andersen violated its industry specifications as a famous certified public accountant.

\subsection{From Corporation's Angle}

The acts of a corporation's managers are attributed to the corporation so long as the managers act within their authority. However, the shareholders of Enron didn't know and realize this matter from the superficial high stock price. Therefore, the whole corporation was not of responsibility for this scandal. Actually, if the board and other shareholders paid more attention to those decisions made by the chief, CEO, CFO and those relevant staffs, ENRON can avoid this result.

\section{The warning of Enron's scandal}

(1) There should be a healthy corporate culture in a company. In Enron's case, its corporate culture played an important role of its collapse. The senior executives believed Enron had to be the best at everything it did and the shareholders of the board, who were not involved in this scandal, were over optimistic about Enron's operating conditions. When there existed failures and losses in their company performance, what they did was covering up 
their losses in order to protect their reputations instead of trying to do something to make it correct. The "to-good-to-be-true" should be paid more attention by directors of board in a company.

(2) A more complete system is needed for owners of a company to supervise the executives and operators and then get the idea of the company's operating situation. There is no doubt that more governance from the board may keep Enron from falling to bankruptcy. The boards of directors should pay closer attention on the behavior of management and the way of making money. In addition, Enron's fall also had strikingly bad influence on the whole U.S. economy. Maybe the government also should make better regulations or rules in the economy.

(3) "Mark to market" is a plan that Jeffrey Skilling and Andrew Fastow proposed to pump the stock price, cover the loss and attract more investment. But it is impossible to gain in a long-term operation in this way, and so it is clearly immoral and illegal. However, it was reported that the then US Security and Exchange Commission allowed them to use "mark to market" accounting method. The ignorance of the drawbacks of this accounting method by SEC also caused the final scandal. Thus, an accounting system which can disclose more financial information should be created as soon as possible.

(4) Maybe business ethics is the most thesis point people doing business should focus on. As a loyal agent of the employer, the manager has a duty to serve the employer in whatever ways will advance the employer's self-interest. In this case, they violated the principle to be loyal to the agency of their ENRON. Especially for accountants, keeping a financial statement disclosed with true profits and losses information is the basic responsibility that they should follow.

\section{References}

Gillan SL, \& Martin JD. (2007). Corporate governance post-Enron: Effective reforms, or closing the stable door? Journal of Corporate Finance, 13(5): 929-958. (December 2007)

He Xuefei. (2008). The Responsibility of False Accounting and Governance. Journal of Central South University of Forestry \& Technology (Social Sciences), 2(4): 69-72.

Larry Rittenberg, Mark A. Covaleski. (2001). Internalization versus externalization of the internal audit function: an examination of professional and organizational imperatives. Accounting, Organizations and Society, 26: 617-641.

Luo Yunxuan and Peng Zhijun. (2002). The Analysis on Effecting a Radical Cure Accounting Fraud by the Corporations Which Have Come into the Market from Enron Company Bankruptcy. Economy \& Auditstudy, 17(4):32-35.

Nelson KK, Price RA, \& Rountree BR. (2008). The market reaction to Arthur Andersen's role in the Enron scandal: Loss of reputation or confounding effects?. Journal of Accounting \& Economics, 46(2-3): 279-293. (December 2008)

NEWS CD-ROM: Enron's Fall In Manuel G. Velasquez, Business Ethics, A Teaching and Learning Classroom Edition: Concepts and Cases, 6/E. upper saddle river, New Jersey: Pearson Education Inc. pp.53-55

Robert Bricker, Kenneth Borokhovich and Betty Simkins. (2003). Critical Perspectives on Accounting. The Impact of Accounting Research on Finance, 14:13-15. (February 2002)

Shen Zhenyu, Wang Jinsheng and Xue Shuang. (2004). Orientation Conflict of Accounting Standards Setting. Journal of Finance and Economics, 30(6): 77-85.

The Conference Board, Inc., 845 Third Avenue, New York, NY 10022-6679. [Online] Available: www.conference-board.org.

Thomas, Booth Cathey. (2002). Called to Account. [Online] Available: http:// www.time.com/time/business/article/0,8599,263006,00.html (April 7, 2010)

Wang Xiaoyan, Zhang Guoqing and Sun Lifeng. (2006). Apocalypse to China Accountant Work from the Accountant Reform after Enron Time. Journal of North China Institute of Water Conservancy and Hydroelectric Power (Social Science), 22(4): 37-39.

Xu Huanzhang, Peng Lilin and Li Panghui. (2005). Analysis of the strategies of avoiding the accounting fabrication. Journal of Xi'an University of Engineering Science and Technology, 19(4): 469-473.

Xu Jing. (2005). Profound Considerations about the Enron Event. Sci/Tech Information Development \& Economy, 15(8): 116-118. 
Table 1. A survey of American's view of lessons and consequences from Enron case

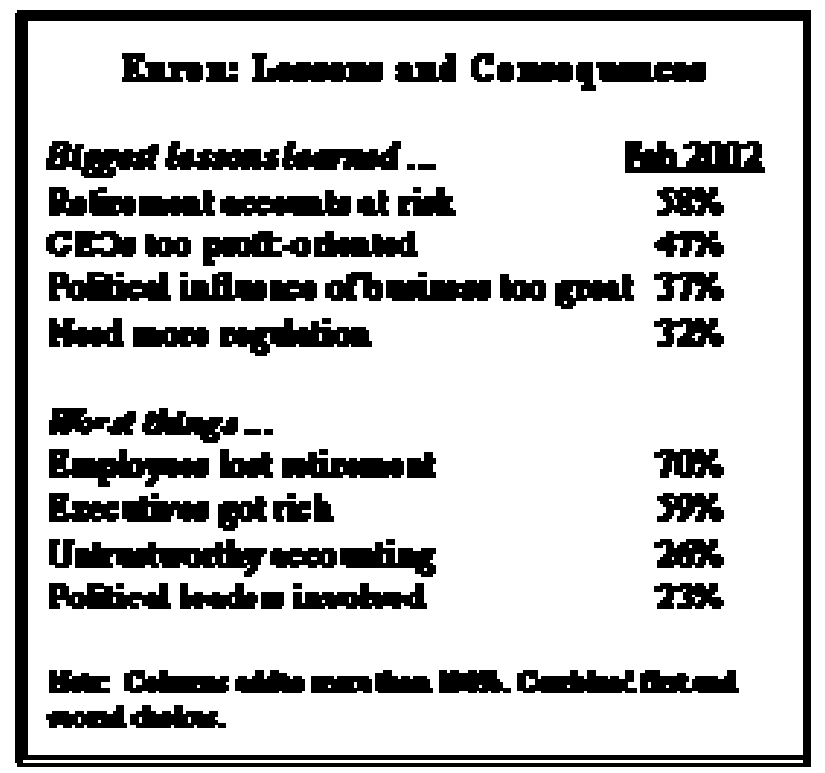

Source: the Pew Research Center for the People \& the Press

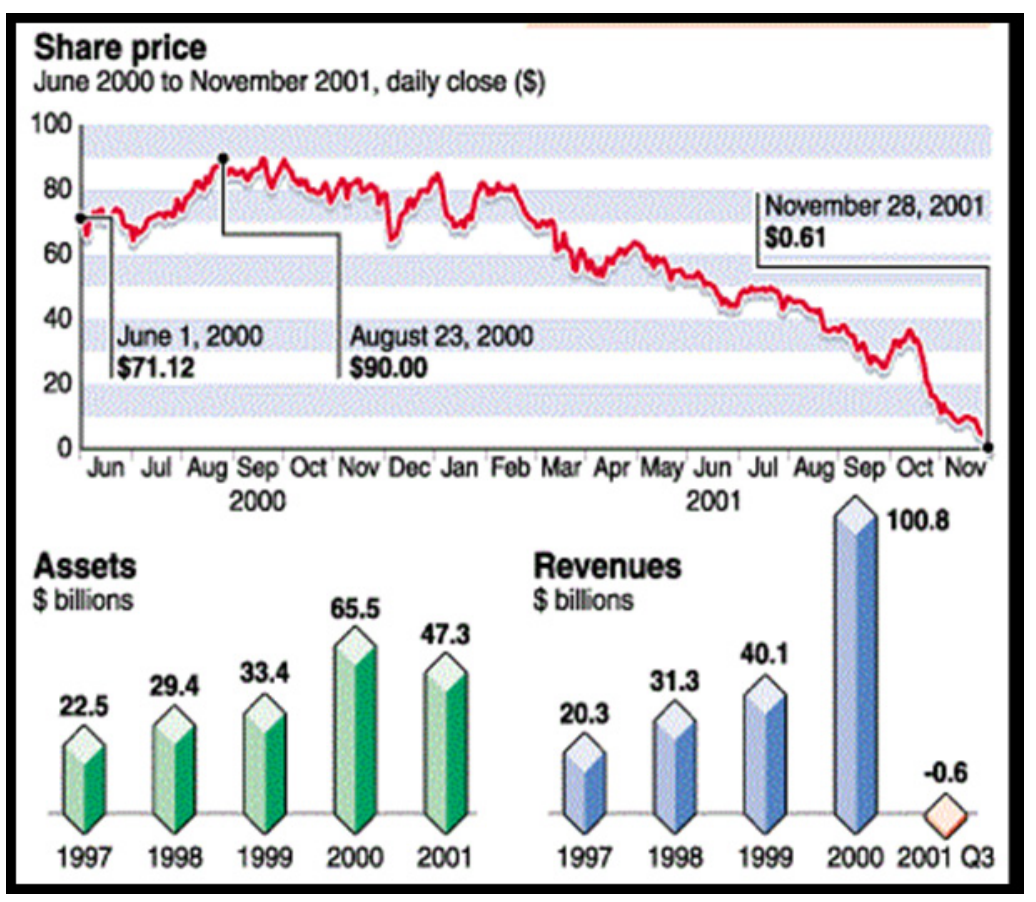

Source: www.enron.com

Figure 1. The Stock Price per Share, Assets and Revenues of Enron before Bankruptcy 